\title{
Active travel: a climate change mitigation strategy with co-benefits for health
}

\section{Chris E. Rissel}

Health Promotion Service, Sydney South West Area Health Service School of Public Health, University of Sydney

Email: criss@email.cs.nsw.gov.au

\begin{abstract}
Reducing the burning of fossil fuels for transport will help reduce the rate of climate change and the severity of the impact of climate change. The alternatives to private motor vehicles include active travel modes such as walking, cycling and use of public transport. While simultaneously reducing carbon dioxide emissions and traffic congestion, active transport leads to increased levels of physical activity and social interaction. This article summarises a number of NSW active travel initiatives. Despite some positive steps in NSW, other Australian states have invested far more and can demonstrate greater changes in travel behaviour.
\end{abstract}

New South Wales (NSW) per capita greenhouse gas emissions are in the order of 23 tonnes per person each year, which is more than double that of the United Kingdom, Germany and Japan (with emissions at just over 10 tonnes per person) and almost double the average for industrialised nations (about 13 tonnes). ${ }^{1}$ Transport emissions include those from road (cars, buses and trucks), rail, shipping and aviation for both passengers and freight, and represent the second largest source of emissions $(14 \%){ }^{2}$

Reducing the burning of fossil fuels for transport will help reduce the rate of climate change and the severity of the impact of climate change. A number of factors are now simultaneously contributing to higher oil and petrol prices, which are likely to have the effect of reducing the consumption of fossil fuels for transport. If Australian government policy introduces an emissions trading scheme that includes transport, the price of (carbon-based) petrol will increase.

Even greater increases in price will come from oil supply crises (e.g. natural disasters such as Hurricane Katrina, or threats to the oil supply from terrorists). Ultimately, demand for oil will exceed supply (which is finite) as the economies of China and India continue to grow. This situation is likely within our lifetime. ${ }^{3-5}$ Already Australians are looking at the cost of driving motor vehicles and thinking about driving less, and the shift away from cars is expected to become more pronounced as petrol prices inevitably rise and concern about climate change increases.

\section{Transport is a social determinant of health}

Although transport is not a traditional focus for health services, it is recognised internationally as a social determinant of health. ${ }^{6}$ As well as being a source of greenhouse gas emissions and other air pollutants, the transport system contributes to injury rates and congestion, and affects access to services and social activities. As transport costs increase, transport and transport availability will increasingly be an issue of equity. Transport deserts areas without reasonable access to public transport - have already been identified in parts of western Sydney, and people living in such areas will be increasingly disadvantaged. ${ }^{7}$ People who cannot afford to drive will need other transport options, such as public transport and bicycle paths. It will be the responsibility of government to ensure that this infrastructure is provided. As Enrique Peñalosa, former mayor of Bogata, Colombia, said, 'A safe cycle path is a symbol of democracy; it shows that a person on a $\$ 40$ bicycle is as important as a person in a $\$ 40000$ car' (personal communication, July 2008).

The alternatives to private motor vehicle-oriented transport include active travel modes such as walking, cycling and use of public transport, either for the whole or part of journeys. While simultaneously reducing carbon dioxide emissions and traffic congestion, active travel leads to increased levels of physical activity, reduced exposure to pollutants (air and noise) and increased social interaction. While the concept of active travel is quite simple, people will default to current practice (i.e. use of the private motor vehicle) unless the alternative travel modes are uncomplicated, safe, easy, affordable and convenient. Active travel is more difficult in settings where there is no or infrequent public transport, or where distances make the time and distance barrier too great to make cycling or walking feasible, as is the case in some outer urban and rural settings. 


\section{NSW initiatives}

In NSW there are a number of initiatives that seek to increase active travel. While these initiatives are usually designed initially to increase physical activity levels, they also have the added benefit of mitigation of climate change. This outcome is in contrast to many other initiatives that represent adaptation and response to climate change (e.g. responding to severe weather events).

In NSW, the Premier's Council for Active Living involves a number of relevant agencies in high level discussions and collaboration. ${ }^{8}$ The role of the Council is to "provide leadership and advice to the Premier to encourage more people to be more active more often' by working collaboratively with senior representatives from government, industry and community sector. Projects tend to be of statewide significance, and include:

- work with a developer to incorporate active living design considerations in new housing developments

- incorporation of active living physical environment characteristics into Metrix, a proposed tool that the Department of Planning is developing to evaluate local councils' local environmental plans

- input into the urban design code for new housing release areas

- work with the NSW State Property Authority to incorporate end-of-trip facilities (such as secure bicycle parking, showers and change rooms) within refurbished buildings when government agencies relocate

- co-ordination of a new whole-of-NSW government Bicycle Plan

- co-ordination of a high level government agency active transport roundtable.

Specific government agencies have also developed guidelines for planners and engineers responsible for building the urban environment that can positively or negatively influence physical activity and active travel. ${ }^{9}$ The former NSW Department of Infrastructure, Planning and Natural Resources in conjunction with the Roads and Traffic Authority (RTA) developed planning guidelines for walking and cycling, and the RTA runs training programs for local government engineers, who are in a position to apply these guidelines to the building of specific local environments. ${ }^{10}$ The RTA also conducts free courses in how to prepare transport access guides. Other agencies such as the National Heart Foundation of Australia have also produced similar documents that highlight the benefits of designing urban environments to facilitate walking and cycling. ${ }^{11}$

\section{Sydney South West Area Health Service initiatives}

There are many examples of local programs that promote active travel. The Sydney South West Area Health Service (SSWAHS) has implemented a number of programs over the last decade. One such program was a health service worksite program involving social marketing and an individual travel behaviour change program that led to modest changes in driving to work and reduced car travel on weekends. ${ }^{12}$ Another strategy has been the development of transport access guides for major trip generators such as hospitals. ${ }^{13}$ These guides illustrate how to travel to and from the hospitals through active travel by showing where the locations of cycle paths, recommended walking routes from rail stations and bus stops (including an indication of the frequency of buses). By not showing parking stations and making active travel easier, this strategy is intended to influence the decision of how to travel to these specific destinations.

An innovative research program underway in SSWAHS is promoting cycling in two local government areas (with a third as a comparison area). The Cycling Connecting Communities project will test whether promoting the use of cycling infrastructure such as new cycle paths in the Fairfield and Liverpool areas will increase overall levels of physical activity in the community. ${ }^{14}$ It will focus on adults, and particularly those people who do not currently ride bicycles, with a wide range of strategies. This project continues earlier cycling promotion work involving the development of a cycling proficiency course to increase the skills and confidence of people wanting to ride more, and the development of a staff bicycle pool. ${ }^{15,16}$

Two other programs in SSWAHS have focused on active travel to school. One is the Central Sydney Walk to School Trial, involving 24 primary schools in the inner west of Sydney and the other is the NSW TravelSmart Schools Program involving 15 primary schools in the inner west and eastern suburbs of Sydney. ${ }^{17,18}$ Both programs had a modest influence on travel behaviour, and highlighted that it is the parent journey to work that is a key factor that influences parents' decisions on how they and their children travel to and from school. ${ }^{19}$ Interestingly, most of the walk-to-school programs internationally have had small effects. In contrast, a well-funded program in California sought to change the physical environment around schools and the main routes to schools. ${ }^{20}$ This program is probably the most successful of any in the world in increasing the number of children actively travelling to school.

With cycling the lowest of the active travel modes, there is considerable potential to increase the proportion of trips by bicycle. Cycling is the fourth most popular form of recreational sport or exercise in Australia, and the Australian Bureau of Statistics census indicates that the journey to work by bicycle has consistently increased over the last decade, with a $22 \%$ increase across Australia from 2001 to 2006..$^{21,22}$ Almost half (42\%) of all households in Sydney in 2005 had a bicycle and new bicycles have consistently outsold new cars for each of the last eight years in Australia. ${ }^{23,24}$

\section{Investment in cycling produces outcomes}

Despite some positive steps towards a greater emphasis on active transport in NSW, other Australian states have 
invested far more and can demonstrate greater changes in travel behaviour. For example, investment in cycling infrastructure over the last decade in Melbourne (up to $\$ 13$ million per annum) has led to increases in cycling from 2001 to 2006 of $42 \% .^{22,25}$ In comparison, cycling in Sydney has increased only 9\%, with the RTA spending \$7 million across NSW in 2006-07 (see Table 1). ${ }^{26}$ The city of London, as part of their Climate Action Plan, has increased funding for cycling and walking by almost five-fold - from $£ 13$ million a year in 2003-04 to £62 million in 2008-09. ${ }^{27}$

Analysis of the 1980 to 1987 Fremantle Network Bike Plan found that it was a worthwhile economic investment for the community, with a $12 \%$ annual increase in the cycling population resulting in transport and health savings to that community of $\$ 420000$ per annum, compared to the implementation costs of the bike plan of $\$ 273000$ per annum. ${ }^{28}$ In addition to social and environmental benefits, there was a benefit-to-cost ratio, in economic terms alone, of $1.46: 1 .{ }^{28}$

A recent review of transport and health promotion interventions to increase levels of cycling found that, despite varying levels of research rigour, most programs did lead to a positive increase in cycling. ${ }^{29}$ An investment in infrastructure for cycling and social and behavioural programs

Table 1. Investment in cycling* and change in cycling usage for journeys to work by Australian capital cities, 2001 to 2006

\begin{tabular}{|c|c|c|}
\hline & $\begin{array}{l}\text { Annual investment } \\
\text { in cycling }\left(\${ }^{\prime} 000 \mathrm{~s}\right)^{*}\end{array}$ & $\begin{array}{l}\text { Journey to work by } \\
\text { bicycle - ABS data } \\
\text { (\% change } 2001 \\
\text { to 2006) }\end{array}$ \\
\hline Sydney & $7000^{* * a}$ & 9 \\
\hline Melbourne & $13000^{b}$ & 43 \\
\hline Adelaide & $3450^{* * b}$ & 31 \\
\hline Hobart & $750^{* * \mathrm{~b}}$ & 25 \\
\hline Perth & $9750^{b}$ & 16 \\
\hline Canberra & $2950^{b}$ & 16 \\
\hline Brisbane & $17000^{c}$ & 13 \\
\hline Darwin & $1270^{d}$ & -7 \\
\hline \multicolumn{3}{|c|}{$\begin{array}{l}\text { Per capita expenditure has not been calculated as the scope of expen- } \\
\text { diture varies by the nature of the geographic areas covered (e.g. city } \\
\text { council, greater metropolitan area, or statewide). }{ }^{*} \text { Expenditure by state } \\
\text { authority responsible for roads/traffic. }{ }^{* *} \text { Expenditure is across the state. } \\
\text { Source: a Roads and Traffic Authority. RTA Annual Report 2007: p. } 60 \text {. } \\
\text { (Cited } 24 \text { July 2008.) Available from: http://www.rta.nsw.gov.au/ } \\
\text { publicationsstatisticsforms/downloads/2007_rta_annualreport_ } \\
\text { mainbody.pdf bCycling Promotion Fund. State and Territory Spending } \\
\text { on Cycling. Cycling Promotion Fund, Melbourne (2007). 'Brisbane City } \\
\text { Council. Council Budget - Moving Brisbane. (Cited } 11 \text { December } \\
\text { 2008.) Available from:http://www.brisbane.qld.gov.au/bccwr/lib513/ } \\
\text { budget0809_moving_brisbane.pdf }{ }^{d} \text { City of Darwin. 2008/2009 City of } \\
\text { Darwin Annual Plan and Budget. (Cited } 11 \text { December 2008.) Available } \\
\text { from: http://www.darcity.nt.gov.au/documents/2008-09AdoptedCity } \\
\text { ofDarwinAnnualPlanandBudget_000.pdf }\end{array}$} \\
\hline
\end{tabular}

that encourage cycling will readily lead to more Australians cycling.

\section{Recommendations to increase cycling}

The barriers to more Australians cycling are relatively well known. ${ }^{30}$ A report commissioned by the Australian Department of Health and Ageing seeking to raise population levels of physical activity identified the barriers and recommended strategies that a whole-of-government approach could use to increase levels of cycling. ${ }^{22}$ These recommendations are largely dependent upon each other and would need to be implemented in an integrated, co-ordinated way:

- Improved bicycle infrastructure: to provide safe, attractive and enjoyable on and off road bicycle routes as well as high quality end-of-trip facilities.

- Funding: to better reflect the role and value of cycling in a range of areas, including transport, health and sustainability, with support from all levels of government.

- Mass marketing campaigns: to promote the multiple health, environmental, transport, economic and social inclusion benefits of cycling, and address perceived barriers such as safety, required fitness level and roaduser behaviour. These campaigns can be supported through the extensive network of cycling organisations around Australia, and should be combined with infrastructure improvements.

- Behaviour change programs such as TravelSmart, Ride to Work and Ride to School programs: to help more Australian children and adults make the daily commute by bicycle.

- Bicycle events: to encourage infrequent and novice riders to cycle in a supportive social environment.

- Bicycle education programs: to increase confidence and skill levels in both the child and adult population.

- Urban design: to create a physical environment more conducive to cycling, such as higher density, mixed use development and shorter trip distances.

Cycling is a carbon-neutral, petrol-free form of transport, simultaneously helping Australians fight climate change, reduce fuel costs and increase physical activity and improve health. As Australian society comes to terms with global warming and the need to change personal behaviour to slow the rate of climate change, active travel needs to be a central platform in this program. Political will is necessary to create an environment that facilitates walking and cycling, as well as public transport options, for all.

\section{References}

1. NSW Department of Environment and Climate Change. What are greenhouse emissions in NSW? Sydney: NSW Department of Environment and Climate Change; 2008. Available from: http://www.environment.nsw.gov.au/climatechange/ emissionsoverview.htm (Cited 18 October 2008.)

2. Department of Climate Change. State and Territory Greenhouse Gas Inventories 2006. Canberra: Australian Government; 2008. 
Available from: http://www.greenhouse.gov.au/inventory/ stateinv/pubs/states2006.pdf (Cited 27 June 2008.)

3. Parker AA. The end of suburbia: what will happen when all the cheap oil is gone and what are the health implications? Health Promot J Austr 2005; 16(1): 61-8.

4. Rissel C. What price petrol? Health Promot J Austr 2006; 17(1): $3-4$

5. Deffeyes KS. Hubbert's Peak: the impending world oil shortages. Princeton, New Jersey: Princeton University Press; 2003.

6. McCarthy M. Transport and health. In: Marmot M, Wilkinson RG, editors. Social Determinants of Health. Oxford: Oxford University Press; 1999. pp. 132-54.

7. Gordon-Larsen P, Nelson MC, Page P, Popkin BM. Inequality in the built environment underlies key health disparities in physical activity and obesity. Pediatrics 2006; 117(2): 417-24 doi:10.1542/peds.2005-0058

8. Premier's Council for Active Living. What is the Premier's Council for Active Living? Sydney: Premier's Council for Active Living; 2008. Available from: http://www.pcal. nsw.gov.au/ (Cited 22 July 2008.)

9. Gebel K, King L, Bauman A, Vita P, Gill T, Rigby A et al. Creating Healthy Environments - A review on the links between the physical environment, physical activity and health. Sydney: NSW Health Department and NSW Centre for Overweight and Obesity; 2005. Available from: http://www.coo.health.usyd. edu.au/publications/creatin.php (Cited 29 July 2008.)

10. NSW Department of Infrastructure, Planning and Natural Resources and the Roads and Traffic Authority. Planning Guidelines for Walking and Cycling NSW Department of Infrastructure, Planning and Natural Resources. Sydney: Roads and Traffic Authority; 2004.

11. National Heart Foundation of Australia (Victorian Division). Healthy by design: a planner's guide to environments for active living. Melbourne: National Heart Foundation of Australia (Victorian Division); 2004. Available from: http://www. heartfoundation.org.au/SiteCollectionDocuments/ Healthy\%20by\%20Design.pdf (Cited 29 July 2008.)

12. Wen LM, Orr N, Bindon J, Rissel C. Promoting active transport in a workplace setting: evaluation of a pilot study in Australia. Health Promot Int 2005; 20(2): 123-33. doi:10.1093/heapro/dah602

13. Bresciani E, Wen LM, Rissel C, Alley J, Jochelson T. Promoting active transport: where to start? Environ Health 2002; 2(1): 55-60

14. Health Promotion Service, Sydney South West Area Health Service. Cycling Connecting Communities. Sydney: Sydney South West Area Health Service; 2008. Available from: http://cyclingconnectingcommunities.wordpress.com/ (Cited 23 July 2008.)

15. Telfer B, Rissel C, Bindon J, Bosch T. Encouraging cycling through a pilot cycling proficiency training program among adults in central Sydney. J Sci Med Sport 2006; 9(1-2): 151-6. doi:10.1016/j.jsams.2005.06.001

16. Rissel C, Telfer B. Managing risk in a workplace bicycle pool. J Australas Coll Road Safety 2005; 16(1): 18-24.
17. Fry D, Wen LM, Merom D, Dirkis H, Rissel C, Balafas A. Final Report of the Central Sydney Walk to School Research Program 2004-2007. Camperdown: Health Promotion Service, Sydney South West Area Health Service; 2008.

18. Fry D. NSW TravelSmart Schools Program 2006-2007 Summary Report. Sydney: NSW Ministry of Transport, SSWAHS and Australian Greenhouse Office; 2008.

19. Wen LM, Fry D, Rissel C, Dirkis H, Balafas A, Merom D. Factors associated with children being driven to school: implications for walk to school programs. Health Educ Res 2008; 23(2): 325-34. doi:10.1093/her/cym043

20. Boarnet MG, Anderson C, Day K, McMillan T, Alfonzo M. Evaluation of the California Safe Routes to School legislation: Urban form changes and children's active transportation to school. Am J Prev Med 2005; 28(2): 134-40. doi:10.1016/ j.amepre.2004.10.026

21. Australian Sports Commission. Participation in Exercise Recreation and Sport - Annual Report 2006. Canberra: Australian Sports Commission; 2006.

22. Bauman A, Rissel C, Garrard J, Ker I, Speidel R, Fishman E. Cycling - Getting Australia Moving: Barriers, facilitators and interventions to get more Australians physically active through cycling. Melbourne: Cycling Promotion Fund; 2008.

23. Ministry of Transport and Roads and Traffic Authority. Cycling in Sydney - Bicycle ownership and use. Sydney: Ministry of Transport and Roads and Traffic Authority; 2008.

24. Cycling Promotion Fund. Bicycle Outsells cars in Australia sales top 1.4 million. Melbourne: Cycling Promotion Fund; 2008. Available from: http://www.cyclingpromotion.com.au/ latest-news/page_3.html (Cited 24 July 2008.)

25. Bicycle Victoria. Transport and Liveability Statement provides \$72 million for riders. Melbourne: Bicycle Victoria; 2007. Available from: http://www.bv.com.au/change-the-world/ 12064 (Cited 24 July 2008.)

26. Roads and Traffic Authority. RTA Annual Report 2007. Sydney: Roads and Traffic Authority; 2007. p. 60. Available from: http:/www.rta.nsw.gov.au/publicationsstatisticsforms/ downloads/2007_rta_annualreport_mainbody.pdf (Cited 24 July 2008.)

27. Cycling Promotion Fund. London increases its cycling budget. Melbourne: Cycling Promotion Fund; 2008. Available from: http://www.cyclingpromotion.com.au/latest-news/latest/ london-increases-its-cycling-budget.html (Cited 24 July 2008.)

28. Campbell R. Bicycle Friendly City [online]. In: 1989 National Transport Conference: Transport for the Users; Preprint of Papers. Barton, ACT: Institution of Engineers, Australia; 1989. pp. 214-8. National conference publication (Institution of Engineers, Australia); no. 89/7. Available from: http://search. informit.com.au/documentSummary; $\mathrm{dn}=820558195016115$; res=IELENG (Cited 15 October 2008.)

29. Rissel C, Garrard J. Cycling for active transport and recreation in Australia: status review and future directions. World Transp Policy Pract 2006; 13(1): 49-63.

30. Daley M, Rissel C, Lloyd B. All dressed up and no-where to go? A qualitative research study of the barriers and enablers to cycling in inner Sydney. Road Transport Res 2007; 16(4): 42-52. 